\title{
Development and evaluation of a food environment survey in three urban environments of Kunming, China
}

Jenna Hua ${ }^{1 *}$,Edmund Seto ${ }^{2}$, Yan $\mathrm{Li}^{3}$ and May C Wang ${ }^{4}$

\begin{abstract}
Background: Given the rapid pace of urbanization and Westernization and the increasing prevalence of obesity, there is a need for research to better understand the influence of the built environment on overweight and obesity in world's developing regions. Culturally-specific food environment survey instruments are important tools for studying changing food availability and pricing. Here, we present findings from an effort to develop and evaluate food environment survey instruments for use in a rapidly developing city in southwest China.

Methods: We developed two survey instruments (for stores and restaurants), each designed to be completed within 10 minutes. Two pairs of researchers surveyed a pre-selected 1-km stretch of street in each of three socio-demographically different neighborhoods to assess inter-rater reliability. Construct validity was assessed by comparing the food environments of the neighborhoods to cross-sectional height and weight data obtained on 575 adolescents in the corresponding regions of the city.
\end{abstract}

Results: 273 food establishments (163 restaurants and 110 stores) were surveyed. Sit-down, take-out, and fast food restaurants accounted for 40\%,21\% and 19\% of all restaurants surveyed. Tobacco and alcohol shops, convenience stores and supermarkets accounted for $25 \%, 12 \%$ and $11 \%$, respectively, of all stores surveyed. We found a high percentage of agreement between teams (>75\%) for all categorical variables with moderate kappa scores (0.4-0.6), and no statistically significant differences between teams for any of the continuous variables. More developed inner city neighborhoods had a higher number of fast food restaurants and convenience stores than surrounding neighborhoods. Adolescents who lived in the more developed inner neighborhoods also had a higher percentage of overweight, indicating well-founded construct validity. Depending on the cutoff used, $19 \%$ to 36\% of male and $10 \%$ to $22 \%$ of female 16 -year old adolescents were found to be overweight.

Conclusions: The prevalence of overweight Chinese adolescents, and the food environments they are exposed to, deserve immediate attention. To our knowledge, these are the first food environment surveys developed specifically to assess changing food availability, accessibility, and pricing in China. These instruments may be useful in future systematic longitudinal assessments of the changing food environment and its health impact in China.

Keywords: Food environment, Nutrition, Construct validity, Survey, Neighborhood, Adolescent, Kunming, China

\footnotetext{
* Correspondence: jenna_hua@berkeley.edu

'School of Public Health, University of California, Berkeley, CA, USA

Full list of author information is available at the end of the article
} 


\section{Background}

The rates of obesity among children and adults in the United States are alarming [1,2] and are responsible for staggering medical costs [3]. Elsewhere, the World Health Organization has declared obesity a global epidemic [4]. Considerable research has been conducted on the complex etiology of obesity, with environmental factors now thought to play an important role in influencing physical activity and diet [5-7]. Given the rapid pace of environmental change, urban development, and Westernization that is occurring in second and third world countries, there is great urgency to better understand the effect of the built environment on obesity and its behavioral risk factors in developing regions of the world. Indeed, in China, obesity rates among children have tripled in just two decades, from 1982 to 2002, reaching rates comparable to those in Western countries [8]. While some well-established larger cities in China already have high rates of obesity [8,9], medium sized cities that are still rapidly developing and currently have relatively lower rates of obesity are opportune sites for place-based research to understand the associations between the changing built environment and obesity. According to epidemiological studies conducted in one such medium sized Chinese city, Kunming, in 2008, it was estimated that $26 \%$ of the adults were overweight [10]. Moreover, in Kunming, the childhood obesity rate in 2008 was $36 \%$ higher than it was in 1996, and three times higher than it was found to be in 1986 [11].

Chinese adolescents who grew up in the 1990s during a period of rapid social and environmental change had increasing access to Western fast food and exposure to new technologies and media that market such food, including the Internet and smartphones. Nearly all were born under China's one-child policy, and were the center of the attention of two generations, giving them the ability to concentrate on their education, but also enormous pressure to meet their parents' and grandparents' high expectations. At the same time, students at this age are highly susceptible to peer pressure [11-15], which influences their dietary patterns and other aspects of their behavior.

Numerous studies have reported associations between food-related aspects of the environment and obesity risk [16-20]. In the U. S. and other Western countries, this research has largely relied on the existence of business, land use, and tax record databases from governmental and commercial sources to characterize the food environment $[17,21]$. However, similar databases are not readily available for rapidly developing countries like China. Moreover, even if such databases were available, their validity would need to be assessed using field surveys.

Field survey instruments can be used to obtain detailed food environment data and to ground-truth food establishment databases. Such instruments allow for quantification of the number of food establishments in neighborhoods, as well as characterization of various aspects of the food offered by these establishments, including the availability and price of fresh and prepared foods that make up typical diets [22,23]. Field survey instruments need to be both reliable and valid. They need to be reliable in that ratings made by different surveyors need to be consistent. Also, among various validity measurements, construct validity is particularly important as it considers how the measures of the instrument relate to the overall theoretical hypotheses [24] - in our case, that the food environment is associated with weight status.

While reliable field survey instruments exist within the Western context [25-28], to our knowledge, no equivalent instruments currently exist to assess the food environment in China. Due to cultural differences in food availability and eating habits, survey instruments used in Western countries cannot be readily applied to China without modification. The development of a culturally appropriate and constructively valid survey instrument for characterizing the Chinese food environment is a critical step toward future studies on the evolution of food environments in a rapidly developing economy and its effects on the health of populations.

The objectives of this study are to: (1) develop a survey instrument for assessing the food environment in China; (2) assess its reliability in a rapidly developing Chinese city; (3) assess its construct validity for the hypothesis that the amount of fast food and packaged food in a Chinese community is positively associated with adolescent weight status; and (4) describe the density and types of food establishments in socioeconomically contrasting neighborhoods in such a city.

\section{Methods}

\section{Survey instrument development}

We developed two survey instruments: one to assess retail food stores and another to assess restaurants. To determine appropriate survey items, we reviewed the literature on food environment assessments via Google Scholar and PubMed, supplemented with a "snowballing" method to search for other relevant information. We found no existing tools appropriate for use in China, as the surveys that are used to assess food environment in United States were culturally inappropriate for the Chinese food environment, specifically the types of foods that are typically on restaurant menus and in food stores. However, the Nutrition Environment Measures Survey (NEMS) instrument used in the U.S. [25,28] provided ideas for conceptualizing the survey instruments, which we created with the assistance of our local Chinese collaborators at the Kunming Medical University. Both 
instruments (for store and restaurant assessment) were designed so that they could be completed within 10 minutes for a single food establishment by surveyors working independently, without disturbing the store or restaurant staff. The survey items and rationale for their inclusion are described in Tables 1 and 2. The two instruments were pretested for wording and content at restaurants, grocery stores and wet markets (open markets where stalls of fresh and prepared foods are sold by different vendors) in Kunming, and then finalized for pilot testing in three socio-demographically contrasting neighborhoods.

\section{Study area}

Kunming is a rapidly developing city that is the capital of Yunnan province, located in the southwest region of China neighboring Tibet, Laos, Vietnam and Burma. Yunnan province has an ethnically diverse population consisting of Han and numerous ethnic minority groups. Because of its geographic location and recently recognized potential to serve as an international logistics center, Kunming has begun to link China with other Southeast Asian countries and is undergoing faster and more dramatic urbanization and environmental change than Beijing or Shanghai did during their peak development periods. Moreover, recent studies suggest that the prevalence of adult overweight and childhood obesity is becoming an increasing problem in Kunming [15,30]. Unless effective intervention strategies are applied, obesityrelated chronic disease rates are expected to increase dramatically $[10,31]$.

\section{Neighborhood selection}

Three neighborhoods varying in distance from the center of Kunming were selected. Like many other Chinese cities, Kunming has concentric ring roads, which radiate from the city center and divide the neighborhoods of the city. Similar to the spatial urban development patterns in many Chinese cities, Kunming was developed according to proximity to the city center. Our study's first neighborhood was situated within the first ring road, the second between the first ring road and the second ring road, and the third outside of the second ring road (Figure 1). These three neighborhoods vary in real estate prices, development histories, and land use characteristics (Table 3). In general, the more central areas of the city are older, with higher real estate and living

Table 1 Items captured by the survey instrument for assessing stores

\begin{tabular}{ll}
\hline Item & Rationale/how measured \\
\hline $\begin{array}{l}\text { Date } \\
\text { Survey start time, survey end time }\end{array}$ & $\begin{array}{l}\text { Essential food establishment data that allows for identification, geocoding, } \\
\text { and time stamping. }\end{array}$ \\
$\begin{array}{l}\text { Food establishment name } \\
\text { Street address }\end{array}$ & \\
GPS reading & \\
Hours of operation &
\end{tabular}

\section{Type of store}

Wet market, supermarket, small market, convenience store, convenience store attached to a gas station, deli, take-out, bakery, street stand/cart, dessert/fruit juice, tobacco/alcohol shop and others

\section{Store size}

Length and width

\section{Types of items sold}

Soy products (raw), packaged foods, frozen meals, fresh cooked/prepared foods, basic grain products, processed/preserved dried meat and seafood, cooking oil, cleaned/easy-to-cook/combo meals, and cold desserts/ice cream

\begin{tabular}{l} 
Indicator food items \\
Salty snack, sweet snack, sweet drinks, alcohol, milk/yogurt, bottled water, \\
powdered drinks, tea, instant noodles, pastry/baked goods, tofu products \\
(packaged snack), fruits, vegetables and fresh meat/poultry \\
\hline For indicator food item that is present.
\end{tabular}

For indicator food item that is present:

Shelf space and product location
For classifying the stores (13 possible types). Categories are modified from those developed by the North American Industrial Classification System (NAICS) [29] used by the United States to classify food establishments. Specifically for Chinese context, even though both are selling cooked or prepared food, a deli is attached to a restaurant, and a take-out store is a stand-alone store. Check all that applied.

Possibly a proxy for food variety. Estimated by assessing the length of a single floor tile and counting the number of perimeter tiles of each rectangular section of a store. (All stores had tiled floors)

For assessing the availability of basic food items. Nine basic food items were assessed. Food item categories were determined by in-person store visit and consultation with local collaborators.

For assessing the availability of specific food items that are indicative of either a healthy or unhealthy diet. Fourteen indicator items were assessed. If available, shelf space and product location were further assessed (see below).

Shelf space assesses whether the indicator item occupies a significant amount of shelf space (significant or not). If certain products occupy more than half of the shelf space, it is counted as significant.

Product location assesses whether the location of the item is in the front, middle, or back of the store. 
Table 2 Items captured by the survey instrument for assessing restaurants

\begin{tabular}{|c|c|}
\hline Restaurant survey variables & Rationale/how measured \\
\hline Date & \multirow{6}{*}{$\begin{array}{l}\text { Essential food establishment data that allows for identification, geocoding, } \\
\text { and time-stamping. }\end{array}$} \\
\hline Survey start time, survey end time & \\
\hline Food establishment name & \\
\hline Street address & \\
\hline GPS reading & \\
\hline Hours of operation & \\
\hline Type of restaurant & \multirow{2}{*}{$\begin{array}{l}\text { Categorization the restaurant. } 14 \text { possible types. Check all that applied. A } \\
\text { distinction was made between establishments that sold prepared foods: if } \\
\text { they had } 5 \text { or more seats, they were defined as restaurants, otherwise } \\
\text { defined as a store. }\end{array}$} \\
\hline $\begin{array}{l}\text { Sit-down, take-out, western fast food, café, Chinese fast food, street } \\
\text { stand/cart, food court, deli, bakery, bar, tea house, dessert, juice bar and } \\
\text { other }\end{array}$ & \\
\hline Restaurant size & \multirow[t]{2}{*}{ Seating capacity in number of persons or number of tables. } \\
\hline Seating capacity & \\
\hline Type of food served & \multirow{2}{*}{$\begin{array}{l}\text { Assess availability of certain types of foods that are common to this city. } \\
11 \text { types. Check all that applied. }\end{array}$} \\
\hline $\begin{array}{l}\text { Vegetarian, vegan, organic, dim-sum, seafood, noodles, regional cuisine, } \\
\text { Muslim, buns/pancakes, deep-fried, and other }\end{array}$ & \\
\hline Drinks & \multirow{2}{*}{$\begin{array}{l}\text { Assess availability of certain types of drinks that are common to this city. } \\
10 \text { types. Check all that applied. }\end{array}$} \\
\hline $\begin{array}{l}\text { None, soda, juice, alcohol, tea, coffee, bottled water, yogurt, flavored milk, } \\
\text { and other }\end{array}$ & \\
\hline Was a take-out menu available? & Yes/no \\
\hline Was a flyer available? & Yes/no \\
\hline Advertisement & \multirow{2}{*}{$\begin{array}{l}\text { Assesses whether the restaurant advertises their food. Check all that } \\
\text { applied. }\end{array}$} \\
\hline None, local TV station, phone directory, newspaper, and other & \\
\hline Display of business license & Indication of potential food quality. Yes/no \\
\hline Website & Indication of new forms of advertising. Yes/no \\
\hline Nutrition information available & Yes/no \\
\hline Signs encouraging overeating & $\begin{array}{l}\text { e.g., all-you-can-eat, super-size, jumbo, extra-large descriptors on menu or } \\
\text { signage. Yes/no }\end{array}$ \\
\hline Promotions & e.g., low-carb, low-fat, low-cholesterol. Yes/no. \\
\hline Portion size choices & $\begin{array}{l}\text { Check if small, medium and large portions sizes are sold. Check all that } \\
\text { applied. }\end{array}$ \\
\hline Price range & \multirow[t]{2}{*}{ Range of pricing for vegetable dishes, meat dishes, and other dishes. } \\
\hline Vegetable, meat, and others & \\
\hline
\end{tabular}

costs, while the less costly outer areas consist of mixtures of urban slums, migrant worker areas, and newer developments that are rapidly replacing older communities. Because socio-demographic data at the neighborhood level was unavailable, we used the average neighborhood real estate prices as a proxy. In each neighborhood, the food environment assessments were carried out on a $1-\mathrm{km}$ stretch of street with visibly high food establishment density. After areas in each neighborhood with high food establishment densities were identified by searching key terms (food establishments, restaurants, food stores, convenience stores, supermarkets and wet markets) at Google and Baidu Maps, 3 streets with highest food establishment densities were identified visually and ranked from first choice to third choice. Distances of 1-km were measured using built-in rulers in Google and Baidu Maps. Prior to conducting surveys, researchers visited the identified streets in each neighborhood to verify the existence and density of the food establishments, and made the final selection of a 1-km stretch of street in each neighborhood.

\section{Reliability}

To assess the inter-rater reliability of the instrument, two pairs of trained student researchers, attempted to survey all food stores and restaurants on each of the pre-selected 1-km stretches of street in the three neighborhoods. Surveys were conducted on weekdays between 10 am and 6:30 pm in July of 2011, with the two pairs of researchers surveying different neighborhoods on a given day to blind each pair to the other pair's activities. If there was any discrepancy between the two researchers within a pair, both returned to the store or 


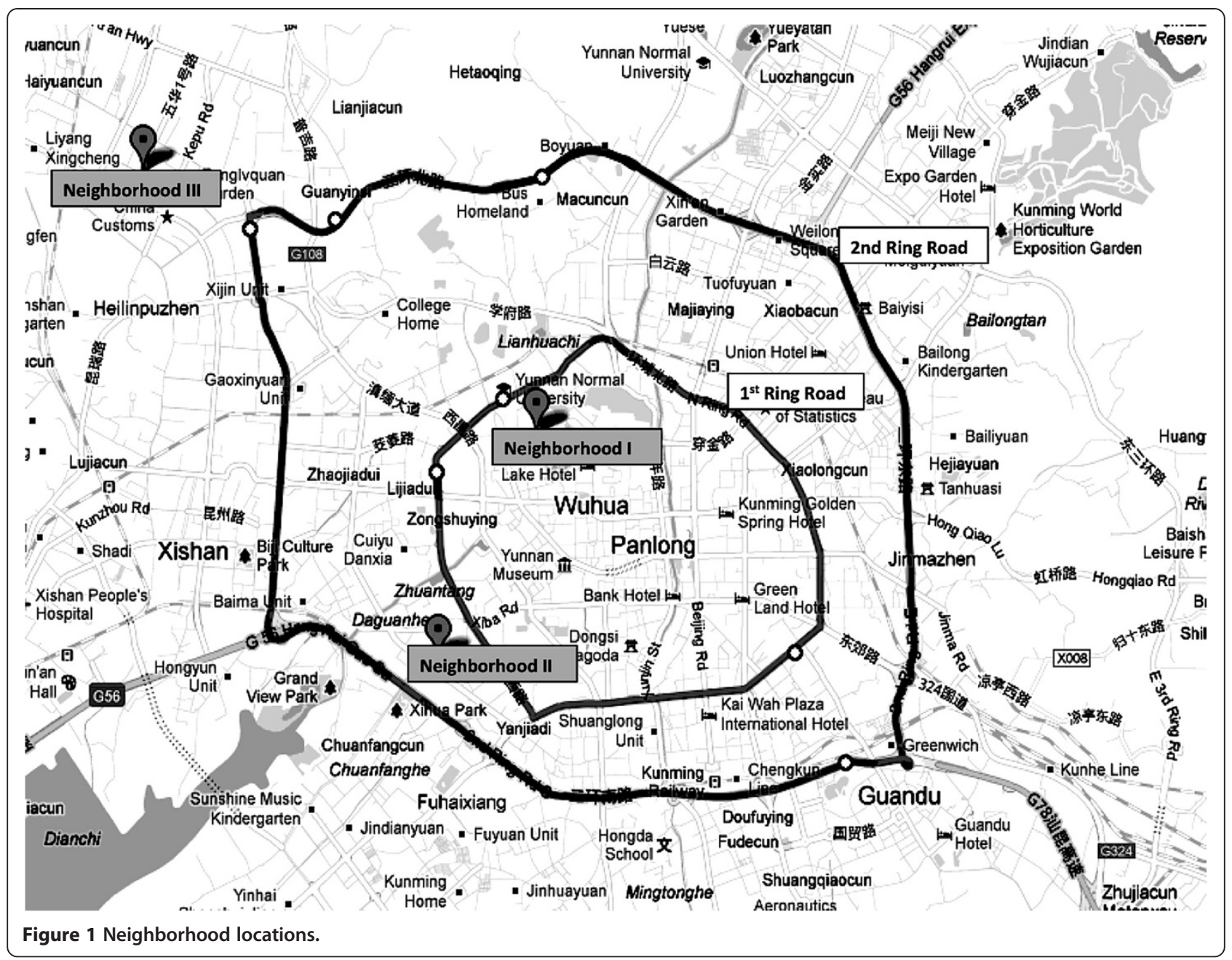

restaurant to make another observation and come to a mutual decision before completing the survey instrument. Having two researchers in a team permitted more efficient and accurate data collection in the field. The student researchers also measured the geographic location of each food establishment by using a GPS unit (Garmin 62S). This paper did not use the geographic location data collected; however, these data may be useful in the future to validate web-based secondary data sources on the food environment such as Google and Baidu Maps. The observations of the two pairs of researchers were compared using appropriate statistical methods as described below.

\section{Evaluation/validity}

To evaluate and assess the construct validity of the instrument, measured heights and weights, as well as approximate home addresses of 575 adolescents from year 2011 were obtained from a local high school. These data were from the high school's routine annual physical assessments of students. The selected high school was located between the first ring and second ring road, but

Table 3 Neighborhood characteristics [32]

\begin{tabular}{|c|c|c|c|c|}
\hline Neighborhoods & Location & $\begin{array}{l}\text { Average real estate price } \\
\left(\mathrm{RMB} / \mathrm{m}^{2}\right) \text { in } 2010\end{array}$ & $\begin{array}{l}\text { Development } \\
\text { history }\end{array}$ & Primary land uses \\
\hline Neighborhood I (Wenlin) & Within the $1^{\text {st }}$ ring & 13,000 & Oldest & Residential, higher education site nearby \\
\hline Neighborhood II (Ankang) & $\begin{array}{l}\text { Between the } 1^{\text {st }} \text { and the } 2^{\text {nd }} \\
\text { ring }\end{array}$ & 9,000 & Newer & Residential \\
\hline $\begin{array}{l}\text { Neighborhood III } \\
\text { (Shangyuan) }\end{array}$ & Outside the $2^{\text {nd }}$ ring & 7,500 & Newest & $\begin{array}{l}\text { Residential, higher educational institution } \\
\text { nearby }\end{array}$ \\
\hline
\end{tabular}


has a wide catchment for students, who lived in various regions of the city. Home addresses were identified by neighborhood, which allowed us to categorize each adolescent's home location in terms of the ring roads. Subjects with missing addresses were excluded from the analysis. Using both the data from the food environment surveys and this cohort's data, we determined the extent to which the prevalence of western-style fast food restaurants and convenience stores (both tending to sell high fat and high caloric foods) is associated with higher prevalence of adolescent overweight and obesity. Adolescents' weights, heights and approximate home addresses were recorded by the researchers without personal identifiers. Use of these de-identified data was approved by the Ethics Committees at Kunming Medical University and the University of California, Berkeley.

The weight statuses of the 575 adolescents were determined by calculating their body mass index (BMI) using their weight in kilograms divided by height in meters, squared. The BMIs were categorized into underweight, normal, overweight and obese. Because there was no single gold standard for BMI criteria for a Chinese population, we used five different BMI cutoffs to demonstrate different distributions of overweight and obese in the cohort. The five BMI cutoffs included those established by the Capital Institute of Pediatrics (CIP) and Working Group on Obesity in China (WGOC), International Obesity Task Force (IOTF), World Health Organization (WHO) and Center for Disease Control (CDC) [33-41]. Additionally, IOTF has two cutoffs, one specifically for Asians. Mean BMI and percentage of overweight adolescents were tabulated by different ring road locations for different genders and ages.

\section{Data analysis}

Differences in counts of different types of food establishments and numbers of overweight or obese by neighborhood were assessed via Fisher's exact test. For comparisons between dichotomous variables, chi-square test was used. The inter-rater reliability of categorical variables was assessed by calculating the percentage of agreement and Cohen's kappa statistic:

$$
\begin{aligned}
& \% \text { agreement }=(A / N) \times 100 \\
& \kappa=\frac{\operatorname{Pr}(A)-\operatorname{Pr}(E)}{1-\operatorname{Pr}(E)}
\end{aligned}
$$

where $A$ is the number of times an item was categorized similarly by the two teams, and $\mathrm{N}$ is the number of stores/restaurants survey by both teams; and kappa is the probability of agreement $\operatorname{Pr}(A)$, adjusted by the probability of chance agreement $\operatorname{Pr}(E)$. Differences in the means of continuous variables estimated by the two teams were assessed with Student's t-test. All tests used statistical significance level of $\mathrm{p}$ value less or equal to 0.05 , and data analyses were conducted using STATA 11.2 (StataCorp, College Station, TX, 2012).

\section{Results \\ Neighborhood comparison}

A total of 273 food establishments including 163 restaurants and 110 retail stores were located on the 3 preselected $1-\mathrm{km}$ stretches of street; data were obtained by both teams on 141 restaurants and 84 retail food stores, and these data were used to calculate inter-rater reliability. The unmatched 48 food establishments that were surveyed by only one of the teams were attributed to food establishments that were not open at the time of survey, as well as food establishments located at the intersection of the selected survey streets and adjacent streets. Sit-down restaurants accounted for almost $40 \%$ of restaurants, while take-out restaurants accounted for $21 \%$. Fast food restaurants (both Western and Chinese) accounted for 19\% of restaurants.

Among retail food stores, tobacco and alcohol shops accounted for nearly $25 \%$ of all stores, while take-out stores, convenience stores, and supermarkets accounted for 14\%, $12 \%$ and $11 \%$ of all stores surveyed, respectively. In addition, there were just two wet markets (open markets that sell fresh produce and meats) in the three neighborhoods surveyed.

With only one street in each of the three neighborhoods sampled, our main objective was not to explore the relationship between neighborhood characteristics and food establishment counts. Nevertheless, we noted that the types and distributions of food establishments varied among the three neighborhoods (Tables 4 and 5). A restaurant or store could be classified into more than one category. For example, a sit-down restaurant selling western fast food would be classified as a sit-down restaurant and also a western fast food outlet. Neighborhood I (the oldest and most expensive neighborhood in the center of the city) had the highest restaurant count, while Neighborhood III (the newest and least expensive neighborhood on the city outskirts) had the second highest restaurant count. Interestingly, the neighborhood that had the highest restaurant count (Neighborhood I) also had the lowest store count. It was also observed that that in the city center, western-style fast food restaurants were prevalent (13 in Neighborhood I vs. 0 and 2 in Neighborhoods II and III respectively), while on the city outskirts, Chinese-style fast food restaurants were relatively more common than western-style fast food restaurants (9 in Neighborhood I vs. 15 and 7 in Neighborhoods II and III). Further, bars and cafes serving snacks/pastries were much more prevalent in Neighborhood I than in the other neighborhoods. 
Table 4 Distribution of restaurants by neighborhood

\begin{tabular}{|c|c|c|c|c|c|c|c|c|}
\hline \multirow{3}{*}{ Restaurant type } & \multirow{3}{*}{ Total count ${ }^{\delta}$} & \multirow{3}{*}{$\%$} & \multicolumn{6}{|c|}{ Neighborhood } \\
\hline & & & \multicolumn{2}{|c|}{1} & \multicolumn{2}{|c|}{ II } & \multicolumn{2}{|c|}{ III } \\
\hline & & & Count & $\%$ & Count & $\%$ & Count & $\%$ \\
\hline Sit-down & 95 & 39.3 & 34 & 29.3 & 24 & 44.4 & 37 & 51.4 \\
\hline Take-out & 52 & 21.5 & 20 & 17.2 & 12 & 22.2 & 20 & 27.8 \\
\hline Chinese fast food & 31 & 12.8 & 9 & 7.8 & 15 & 27.8 & 7 & 9.7 \\
\hline Western fast food & 15 & 6.2 & 13 & 11.2 & 0 & 0 & 2 & 2.8 \\
\hline Café (snacks/pastries) & 14 & 5.8 & 12 & 10.3 & 0 & 0 & 2 & 2.8 \\
\hline Other & 13 & 5.4 & 9 & 7.8 & 1 & 1.9 & 3 & 4.2 \\
\hline Bar & 12 & 5 & 12 & 10.3 & 0 & 0 & 0 & 0 \\
\hline Tea House & 6 & 2.5 & 4 & 3.5 & 1 & 1.9 & 1 & 1.4 \\
\hline Bakery & 2 & 0.8 & 2 & 1.7 & 0 & 0 & 0 & 0 \\
\hline Food court & 1 & 0.4 & 1 & 0.9 & 0 & 0 & 0 & 0 \\
\hline Deli & 1 & 0.4 & 0 & 0 & 1 & 1.9 & 0 & 0 \\
\hline Total & 242 & 100 & 116 & 100 & 54 & 100 & 72 & 100 \\
\hline
\end{tabular}

${ }^{8}$ Categories are not mutually exclusive and a restaurant/store may be counted in more than one category.

\section{Characteristics of foods available}

Selected characteristics of the most common foods offered by restaurants and stores are summarized in Tables 6 and 7. In restaurants, meat dishes tended to be more expensive than vegetable dishes, except at western fast food restaurants. Western fast food restaurants were more likely to offer deep-fried foods than Chinese sit-down, take-out, or even Chinese fast food restaurants. Interestingly, they were also more likely to offer dim-sum (bite-sized foods such as Chinese dumplings) than the other 3 common restaurant types. Chinese fast food consisted mainly of regional cuisine and noodle establishments. In terms of beverages, soda was available at most restaurants whereas bottled water was seldom available. Alcohol of various sorts was available at most restaurants except at sit-down restaurants. Most of the restaurants did not participate in any type of advertising although $3-13 \%$ had websites. Messages that encourage overeating such as "all-you-can-eat" promotions were visibly absent from the restaurants surveyed.

The survey revealed the wide variety of food stores available in Kunming (Table 7). Wet markets were few in number but, when present, they typically carried fresh fruits and vegetables and meat. In contrast, neighborhood supermarkets and convenience stores mostly sold packaged and processed foods and beverages; few carried fresh fruits, vegetables and meats.

Table 5 Distribution of retail food stores by neighborhood

\begin{tabular}{|c|c|c|c|c|c|c|c|c|}
\hline \multirow{3}{*}{ Store type } & \multirow{3}{*}{ Total count $^{\delta}$} & \multirow{3}{*}{$\%$} & \multicolumn{6}{|c|}{ Neighborhood } \\
\hline & & & \multicolumn{2}{|c|}{ I } & \multicolumn{2}{|c|}{ II } & \multicolumn{2}{|c|}{ III } \\
\hline & & & Count & $\%$ & Count & $\%$ & Count & $\%$ \\
\hline Tobacco \& alcohol & 20 & 23.8 & 5 & 26.3 & 13 & 31 & 2 & 8.7 \\
\hline Take-out & 12 & 14.3 & 0 & 0 & 8 & 19.1 & 4 & 17.4 \\
\hline Convenience store & 10 & 11.9 & 5 & 26.3 & 3 & 7.1 & 2 & 8.7 \\
\hline Supermarket & 9 & 10.7 & 1 & 5.3 & 4 & 9.5 & 4 & 17.4 \\
\hline Other & 8 & 9.5 & 2 & 10.5 & 6 & 14.3 & 0 & 0 \\
\hline Bakery & 6 & 7.1 & 2 & 10.5 & 3 & 7.1 & 1 & 4.4 \\
\hline Dessert/fruit juice & 5 & 6 & 0 & 0 & 0 & 0 & 5 & 21.7 \\
\hline Small market & 4 & 4.8 & 2 & 10.5 & 1 & 2.4 & 1 & 4.4 \\
\hline Deli & 4 & 4.8 & 0 & 0 & 2 & 4.8 & 2 & 8.7 \\
\hline Newspaper stand, street stand/cart & 4 & 4.8 & 2 & 10.5 & 0 & 0 & 2 & 8.7 \\
\hline Wet market & 2 & 2.4 & 0 & 0 & 2 & 4.8 & 0 & 0 \\
\hline Total & 84 & 100 & 19 & 100 & 42 & 100 & 23 & 100 \\
\hline
\end{tabular}

${ }^{\delta}$ Categories are not mutually exclusive and a restaurant/store may be counted in more than one category. 
Table 6 Characteristics of four restaurant types

\begin{tabular}{|c|c|c|c|c|}
\hline & \multicolumn{4}{|c|}{ Restaurant type } \\
\hline & Sit-down & Take-out & Western fast food & Chinese fast food \\
\hline Number of establishments & 100 & 54 & 16 & 34 \\
\hline Seating capacity, mean (SD) persons & $81.6(92.6)$ & $57.0(77.6)$ & $96.4(95.8)$ & $103(128)$ \\
\hline \multicolumn{5}{|l|}{ Type of food served } \\
\hline Vegetarian, vegan, or organic & $1 \%$ & $2 \%$ & $6 \%$ & $0 \%$ \\
\hline Dim-sum & $31 \%$ & $28 \%$ & $69 \%$ & $24 \%$ \\
\hline Seafood & $17 \%$ & $9 \%$ & $6 \%$ & $26 \%$ \\
\hline Noodles & $29 \%$ & $35 \%$ & $19 \%$ & $38 \%$ \\
\hline Regional cuisine & $24 \%$ & $20 \%$ & $0 \%$ & $44 \%$ \\
\hline Muslim & $1 \%$ & $2 \%$ & $0 \%$ & $3 \%$ \\
\hline Buns/pancakes & $10 \%$ & $13 \%$ & $0 \%$ & $32 \%$ \\
\hline Deep-fried & $22 \%$ & $20 \%$ & $38 \%$ & $24 \%$ \\
\hline \multicolumn{5}{|l|}{ Drinks } \\
\hline None & $15 \%$ & $26 \%$ & $0 \%$ & $21 \%$ \\
\hline Soda & $74 \%$ & $61 \%$ & $100 \%$ & $62 \%$ \\
\hline Juice & $75 \%$ & $67 \%$ & $88 \%$ & $62 \%$ \\
\hline Alcohol & $6 \%$ & $35 \%$ & $75 \%$ & $62 \%$ \\
\hline Tea & $47 \%$ & $44 \%$ & $75 \%$ & $35 \%$ \\
\hline Coffee & $25 \%$ & $20 \%$ & $81 \%$ & $6 \%$ \\
\hline Bottled water & $9 \%$ & $11 \%$ & $0 \%$ & $12 \%$ \\
\hline Yogurt & $12 \%$ & $6 \%$ & $31 \%$ & $12 \%$ \\
\hline Flavored milk & $15 \%$ & $13 \%$ & $38 \%$ & $9 \%$ \\
\hline Take out menu available & $8 \%$ & $11 \%$ & $31 \%$ & $3 \%$ \\
\hline Flyer available & $4 \%$ & $0 \%$ & $6 \%$ & $6 \%$ \\
\hline \multicolumn{5}{|l|}{ Advertisement } \\
\hline None & $92 \%$ & $94 \%$ & $75 \%$ & $97 \%$ \\
\hline Local TV station & $4 \%$ & $4 \%$ & $6 \%$ & $3 \%$ \\
\hline Phone directory & $4 \%$ & $2 \%$ & $6 \%$ & $3 \%$ \\
\hline Newspaper & $1 \%$ & $0 \%$ & $0 \%$ & $3 \%$ \\
\hline Display of business license & $88 \%$ & $89 \%$ & $75 \%$ & $97 \%$ \\
\hline Website & $4 \%$ & $4 \%$ & $13 \%$ & $3 \%$ \\
\hline Nutrition information available & $0 \%$ & $0 \%$ & $0 \%$ & $0 \%$ \\
\hline Signs encouraging overeating & $0 \%$ & $0 \%$ & $0 \%$ & $0 \%$ \\
\hline Promotions & $0 \%$ & $0 \%$ & $0 \%$ & $0 \%$ \\
\hline Portion size choices & $37 \%$ & $41 \%$ & $25 \%$ & $35 \%$ \\
\hline \multicolumn{5}{|l|}{ Prices (lowest priced) } \\
\hline Vegetable, mean (SD) RMB & $2.31(10.2)$ & $0.93(2.32)$ & $8.25(24.4)$ & $1.13(2.31)$ \\
\hline Meat, mean (SD) RMB & $3.71(8.35)$ & $2.50(6.38)$ & $5.75(13.3)$ & $2.24(3.92)$ \\
\hline
\end{tabular}

\section{Reliability}

Inter-rater reliability between the two survey teams for restaurant and store-related categorical variables is reported in Tables 8 and 9, respectively. In general, the percentage of agreement was high $(>75 \%)$ for all categorical variables, and the average kappa statistics ranged from 0.162 to 0.648 . Most kappa scores were between 0.4 to 0.6 , indicating moderate agreement. The poorer kappa statistics tended to be associated with survey items that were not immediately observable (i.e., required questioning a person from the restaurant or store), such as whether the restaurant advertises or has a 
Table 7 Characteristics of four food store types

\begin{tabular}{|c|c|c|c|c|}
\hline & \multicolumn{4}{|c|}{ Food store type } \\
\hline & Wet market & Supermarket & Small market & Convenience store \\
\hline Number of establishments & 2 & 9 & 4 & 10 \\
\hline Store size, $\mathrm{m}^{2}$ & $8100(2121)$ & $233(360)$ & $59.4(42.6)$ & $37.4(48.0)$ \\
\hline \multicolumn{5}{|l|}{ Types of items sold } \\
\hline Soy products & $100 \%$ & $0 \%$ & $0 \%$ & $10 \%$ \\
\hline Packaged foods & $100 \%$ & $67 \%$ & $0 \%$ & $30 \%$ \\
\hline Frozen meals & $0 \%$ & $11 \%$ & $0 \%$ & $10 \%$ \\
\hline Fresh cooked/prepared foods & $100 \%$ & $0 \%$ & $0 \%$ & $0 \%$ \\
\hline Basic grain products & $100 \%$ & $56 \%$ & $0 \%$ & $20 \%$ \\
\hline Processed/preserved dried meat and seafood & $100 \%$ & $33 \%$ & $0 \%$ & $20 \%$ \\
\hline Cooking oil & $100 \%$ & $56 \%$ & $0 \%$ & $20 \%$ \\
\hline Cleaned/easy-to-cook/combo meals & $0 \%$ & $0 \%$ & $0 \%$ & $0 \%$ \\
\hline Cold dessert/ice cream & $100 \%$ & $78 \%$ & $0 \%$ & $30 \%$ \\
\hline \multicolumn{5}{|l|}{ Indicator food items } \\
\hline Salty snack & $0 \%$ & $100 \%$ & $0 \%$ & $60 \%$ \\
\hline Sweet snack & $0 \%$ & $100 \%$ & $0 \%$ & $60 \%$ \\
\hline Sweet drinks & $100 \%$ & $100 \%$ & $0 \%$ & $67 \%$ \\
\hline Alcohol & $0 \%$ & $100 \%$ & $0 \%$ & $80 \%$ \\
\hline Milk/yogurt & $100 \%$ & $89 \%$ & $0 \%$ & $50 \%$ \\
\hline Bottled water & $100 \%$ & $89 \%$ & $0 \%$ & $70 \%$ \\
\hline Powdered drinks & $0 \%$ & $67 \%$ & $0 \%$ & $70 \%$ \\
\hline Tea & $100 \%$ & $44 \%$ & $0 \%$ & $10 \%$ \\
\hline Instant noodles & $0 \%$ & $78 \%$ & $0 \%$ & $60 \%$ \\
\hline Pastry/baked goods & $100 \%$ & $33 \%$ & $0 \%$ & $50 \%$ \\
\hline Tofu products & $100 \%$ & $33 \%$ & $0 \%$ & $0 \%$ \\
\hline Fruits & $100 \%$ & $0 \%$ & $75 \%$ & $0 \%$ \\
\hline Vegetables & $100 \%$ & $0 \%$ & $0 \%$ & $0 \%$ \\
\hline Fresh meat/poultry & $100 \%$ & $0 \%$ & $0 \%$ & $0 \%$ \\
\hline
\end{tabular}

website. Thus, these person-reported surveys responses may reflect the varying degrees of knowledge of the restaurant staff versus managers or owners. We found no statistically significant differences between teams for any of the continuous variables (Table 10).

\section{Adolescent BMI distributions}

The distribution of 575 adolescents' BMIs is illustrated in Figure 2 with mean BMI of $21.1 \mathrm{~kg} / \mathrm{m}^{2}$ and standard deviation of $3.2 \mathrm{~kg} / \mathrm{m}^{2}$. The percentage distribution of BMI categories for five different cutoffs is reported in Figure 3 and Additional file 1. Mean BMIs and percentages of overweight adolescents at categorized locations, adjusted for gender and age, are reported in Tables 11 and 12 . More than $85 \%$ of the students were between ages 16 and 17. At age 16, IOTF Asian cutoffs generated the highest percentage (35.6\% for male and $21.8 \%$ for female) of overweight (combined overweight and obese) adolescents; WGOC cutoffs generated $21.0 \%$ for males and $11.1 \%$ for females; IOTF regular cutoffs generated $19.8 \%$ for males and $9.9 \%$ for females; WHO cutoffs generated $20.9 \%$ for males and $9.9 \%$ for females, and CDC cutoffs generated the lowest percentage (18.6\% for males and $9.5 \%$ for females). There was higher prevalence of overweight and obesity in males than females. In terms of underweight, CIP's below- $5^{\text {th }}$-percentile cutoff and WHO cutoff generated $2.3 \%$ and $2.0 \%$ of underweight male and female adolescents, IOTF cutoff generated 6.2\% for males and $12.3 \%$ for females, and CDC cutoff generated $5.1 \%$ for males and $3.6 \%$ for females.

\section{Evaluation/validity}

Construct validity of the survey instruments is reported in Tables 11 and 12. There were 30 students with missing home addresses; therefore, a total of 545 students were included in the validity tabulation. In general, 
Table 8 Inter-rater reliability for categorical items: restaurants

\begin{tabular}{|c|c|c|c|c|c|}
\hline Restaurant & Team 1 & Team 2 & $\%$ agreement & Kappa & SE \\
\hline \multicolumn{6}{|l|}{ Type of restaurant } \\
\hline Sit-down & 101 & 100 & 83.9 & 0.6 & 0.084 \\
\hline Take-out & 82 & 54 & 73.4 & 0.5 & 0.077 \\
\hline Western fast food & 6 & 16 & 93.0 & 0.5 & 0.073 \\
\hline Chinese fast food & 5 & 34 & 79.7 & 0.2 & 0.051 \\
\hline Food court & 1 & 1 & 100.0 & 1.0 & 0.084 \\
\hline Deli & 4 & 1 & 97.9 & 0.4 & 0.067 \\
\hline Bakery & 2 & 2 & 100.0 & 1.0 & 0.084 \\
\hline Bar & 37 & 12 & 82.5 & 0.4 & 0.068 \\
\hline Tea house & 2 & 6 & 95.8 & 0.2 & 0.072 \\
\hline Dessert & 7 & 14 & 88.1 & 0.1 & 0.078 \\
\hline Other & 11 & 14 & 88.1 & 0.3 & 0.083 \\
\hline Average & 23 & 23 & 89.3 & 0.5 & 0.075 \\
\hline \multicolumn{6}{|l|}{ Type of food served } \\
\hline Vegetarian & 0 & 1 & 99.3 & 0.0 & N/A \\
\hline Dim-Sum & 25 & 34 & 86.7 & 0.6 & 0.082 \\
\hline Seafood & 22 & 17 & 88.1 & 0.5 & 0.083 \\
\hline Noodles & 31 & 29 & 83.2 & 0.5 & 0.084 \\
\hline Regional cuisine & 12 & 25 & 86.7 & 0.4 & 0.077 \\
\hline Muslim & 3 & 2 & 97.9 & 0.4 & 0.082 \\
\hline Buns/pancakes & 18 & 12 & 93.0 & 0.6 & 0.082 \\
\hline Deep-fried foods & 35 & 25 & 81.8 & 0.5 & 0.082 \\
\hline Other & 18 & 30 & 67.8 & 0.1 & 0.080 \\
\hline Average & 18 & 19 & 87.2 & 0.4 & 0.081 \\
\hline \multicolumn{6}{|l|}{ Drinks } \\
\hline N/A & 43 & 47 & 90.2 & 0.8 & 0.083 \\
\hline Soda & 80 & 82 & 87.4 & 0.7 & 0.084 \\
\hline Juice & 86 & 81 & 85.3 & 0.7 & 0.083 \\
\hline Alcohol & 62 & 67 & 88.1 & 0.8 & 0.083 \\
\hline Tea & 52 & 54 & 84.6 & 0.7 & 0.084 \\
\hline Coffee & 31 & 29 & 88.8 & 0.7 & 0.084 \\
\hline Bottled water & 27 & 11 & 83.2 & 0.3 & 0.074 \\
\hline Yogurt & 21 & 12 & 86.7 & 0.4 & 0.080 \\
\hline Flavored milk & 31 & 17 & 80.4 & 0.3 & 0.079 \\
\hline Other & 8 & 3 & 93.7 & 0.2 & 0.074 \\
\hline Average & 44 & 40 & 86.9 & 0.5 & 0.081 \\
\hline Takeout menu & 76 & 11 & 53.1 & 0.1 & 0.042 \\
\hline Flyers & 41 & 6 & 75.3 & 0.2 & 0.050 \\
\hline \multicolumn{6}{|l|}{ Advertised } \\
\hline N/A & 115 & 134 & 82.5 & 0.3 & 0.069 \\
\hline Local phone directory & 21 & 4 & 86.7 & 0.2 & 0.049 \\
\hline Newspaper & 2 & 1 & 97.9 & 0.0 & 0.079 \\
\hline Local TV station & 8 & 4 & 94.4 & 0.3 & 0.079 \\
\hline Other & 6 & 4 & 93.0 & 0.0 & 0.082 \\
\hline
\end{tabular}


Table 8 Inter-rater reliability for categorical items: restaurants (Continued)

\begin{tabular}{|c|c|c|c|c|c|}
\hline Average & 30 & 29 & 90.9 & 0.2 & 0.072 \\
\hline Business license & 109 & 104 & 85.3 & 0.6 & 0.083 \\
\hline Website available & 6 & 7 & 93.2 & 0.1 & 0.084 \\
\hline Nutrition information & 1 & 0 & 99.3 & 0.0 & N/A \\
\hline Overeating & 2 & 0 & 98.6 & 0.0 & 0.000 \\
\hline Special options & 9 & 0 & 93.7 & 0.0 & 0.000 \\
\hline \multicolumn{6}{|l|}{ Portion choices } \\
\hline N/A & 98 & 104 & 83.2 & 0.6 & 0.083 \\
\hline Small & 44 & 39 & 83.9 & 0.6 & 0.083 \\
\hline Medium & 25 & 12 & 86.7 & 0.4 & 0.077 \\
\hline Large & 43 & 39 & 81.8 & 0.6 & 0.083 \\
\hline Average & 53 & 49 & 83.9 & 0.5 & 0.082 \\
\hline
\end{tabular}

regardless of the cutoffs used, the percentages of overweight adolescents were highest for those who lived within the $1^{\text {st }}$ ring. And, those who lived between the $1^{\text {st }}$ and $2^{\text {nd }}$ ring had higher percentages of overweight than those who lived outside the $2^{\text {nd }}$ ring. Although the differences were small and only marginally statistically significant (Student' t-test $\mathrm{p}=0.077$ to 0.131 between within $1^{\text {st }}$ and outside of $2^{\text {nd }}$ ring groups depending on which cutoff is used), there was consistency with differences in mean BMI between categories for students aged 16 to 17. The mean BMIs of those who lived at three locations were 21.7, 21.4 and $21.3 \mathrm{~kg} / \mathrm{m}^{2}$ (SD 3.58, 3.97, and 3.83) for males, and 21.6, 20.5 and $20.8 \mathrm{~kg} / \mathrm{m}^{2}$ (SD $3.11,2.78$, and 3.55 ) for females, respectively. This was

Table 9 Inter-rater reliability for categorical items: food stores

\begin{tabular}{|c|c|c|c|c|c|}
\hline Food store & Team 1 & Team 2 & $\%$ agreement & Kappa & SE \\
\hline \multicolumn{6}{|l|}{ Type of store } \\
\hline Wet market & 2 & 2 & 100.0 & 1.0 & 0.111 \\
\hline Supermarket & 9 & 9 & 95.1 & 0.8 & 0.111 \\
\hline Small market & 3 & 4 & 96.3 & 0.6 & 0.110 \\
\hline Convenience store & 2 & 10 & 87.7 & 0.1 & 0.080 \\
\hline Deli & 4 & 4 & 100.0 & 1.0 & 0.111 \\
\hline Take-out & 2 & 12 & 87.7 & 0.3 & 0.074 \\
\hline Bakery & 6 & 6 & 100.0 & 1.0 & 0.111 \\
\hline Newspaper stand, street stand/cart & 5 & 4 & 96.3 & 0.7 & 0.110 \\
\hline Dessert/fruit juice & 5 & 5 & 100.0 & 1.0 & 0.111 \\
\hline Tobacco and alcohol shop & 13 & 20 & 86.4 & 0.6 & 0.107 \\
\hline Other & 28 & 8 & 70.4 & 0.2 & 0.084 \\
\hline Average & 7 & 8 & 92.7 & 0.6 & 0.102 \\
\hline \multicolumn{6}{|l|}{ Item sold } \\
\hline Tofu products & 0 & 1 & 98.8 & 0.0 & 0.000 \\
\hline Packaged foods & 10 & 9 & 96.3 & 0.8 & 0.106 \\
\hline Frozen dumplings/meals & 1 & 2 & 98.8 & 0.7 & 0.105 \\
\hline Fresh cooked prepared foods & 0 & 2 & 97.5 & 0.0 & 0.000 \\
\hline Basic grain products & 6 & 7 & 96.3 & 0.7 & 0.111 \\
\hline Processed, preserved dried meat and seafood & 10 & 6 & 95.1 & 0.7 & 0.107 \\
\hline Cooking oil & 9 & 7 & 97.5 & 0.9 & 0.110 \\
\hline Ice cream, cold dessert & 11 & 18 & 86.4 & 0.5 & 0.106 \\
\hline Average & 6 & 7 & 95.8 & 0.5 & 0.081 \\
\hline
\end{tabular}


Table 10 Reliability statistics for restaurant and store continuous variables

\begin{tabular}{lccc}
\hline & $\begin{array}{c}\text { Team 1 mean } \\
\text { (SD) }\end{array}$ & $\begin{array}{c}\text { Team 2 mean } \\
\text { (SD) }\end{array}$ & P \\
\hline Restaurants & & & \\
\hline Seating capacity, persons & $62.4(84.0)$ & $62.6(90.6)$ & 0.99 \\
Vegetable (lowest priced), & $1.41(3.14)$ & $1.72(8.61)$ & 0.68 \\
RMB & & & \\
Meat (lowest priced), RMB & $3.76(10.6)$ & $2.87(7.79)$ & 0.42 \\
\hline Stores & & & \\
\hline Store size, $\mathrm{m}^{2}$ & $44.6(111)$ & $44.9(136)$ & 0.98 \\
\hline
\end{tabular}

also consistent with the distribution of western-style fast food restaurants and convenience stores in three neighborhoods, with the neighborhood within the $1^{\text {st }}$ ring having the highest count of western-style fast food restaurants and convenience stores illustrated in Tables 4 and 5 . This provides indication of validity that the survey is adequately sampling food environments relevant to adolescent obesity.

\section{Discussion}

The development and validation of culturally-specific food environment survey instruments is an important step towards the conduct of studies of changing food availability, access, and pricing in second and third world countries, where obesity rates are rising rapidly. Here, we present the results of an effort, motivated by the use of the NEMS instrument within the American context to study food environments, to develop and validate an instrument for surveying restaurants and food stores in a rapidly developing city in southwest China. Overall, both the restaurant and store food environment instruments were found to have excellent percentage of

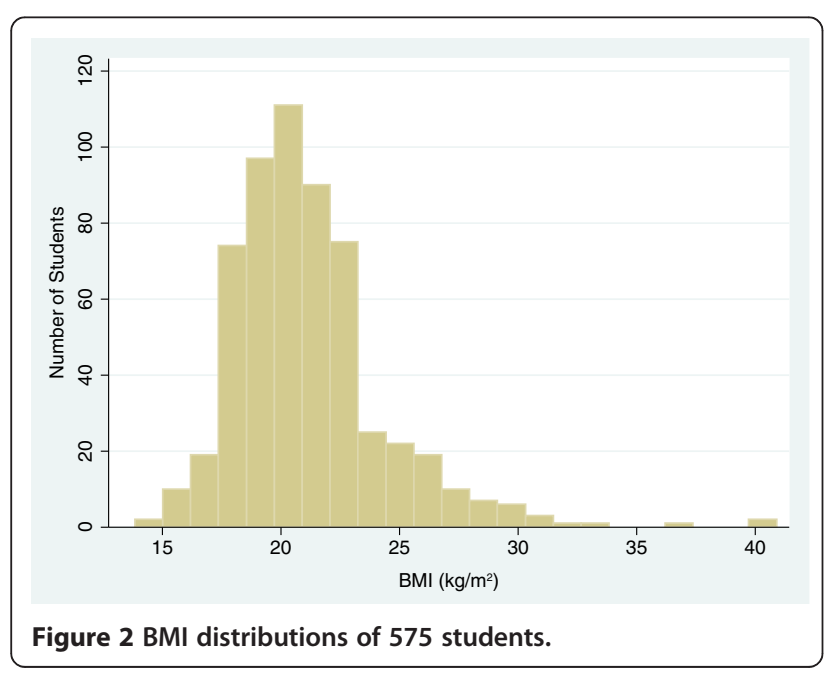

agreement and moderate kappa scores, as well as wellfounded construct validity.

There are limitations to our survey. In particular, restriction to a $1-\mathrm{km}$ stretch of street in only 3 neighborhoods is clearly not representative of all of China or even of all the neighborhoods of Kunming, and by limiting our surveys to 10 minutes, there were many aspects of the food environment that were not recorded. For example, we were unable to properly assess the prices of all food items. We were also unable to properly measure shelf space and instead, developed a rapid assessment technique that involved the counting of floor tiles that were measured at each store. However, our experience during rounds of pilot testing suggested that surveyor fatigue and store/restaurant's unwillingness to cooperate significantly impacted the survey qualities when the surveys were longer than 10 minutes. Despite these limitations, our study of three socio-demographically contrasting neighborhoods provides a fairly rich glimpse of the types of food environment changes that may be occurring as a result of ongoing globalization and the introduction of western-style fast food into other countries' food environments. Unhealthy qualities attributed to fast food were found in our study. In particular, high percentages of deep-fried foods, soda, and snack-like meals were found in restaurants and food stores, and prices of vegetables tended to be higher than those of meat products. Clearly, there is a need for more systematic longitudinal assessments of changing food environments in this cultural context, which could advance understanding of the influences of rapidly changing environments on non-communicable disease risk. Since the development of this instrument in 2011, we have conducted surveys in 2012 and 2013. While it is not the goal of this paper to describe longitudinal changes that may be occurring, as they are multi-faceted and complex, based on our preliminary analyses, the food environment instrument does seem to be sensitive in detecting certain key changes within neighborhoods such as changes in the numbers of sit-down and take-out restaurants, dessert shops, as well as convenience stores.

In contrast to the changes in the prevalence of certain foods that may be occurring with the proliferation of western fast food, some aspects of the food environment remain characteristically Chinese. For example, we found that traditional wet markets remain important places for people in the city to buy fresh fruits, vegetables and meat. In fact, none of the local supermarkets and convenience stores in our three neighborhoods sold these fresh foods. A point of concern is that supermarkets and convenience stores are ubiquitous, with one on nearly every street block, which makes packaged and processed foods and beverages more readily accessible than fresh food from the wet markets. We also observed that wet markets had limited operating 

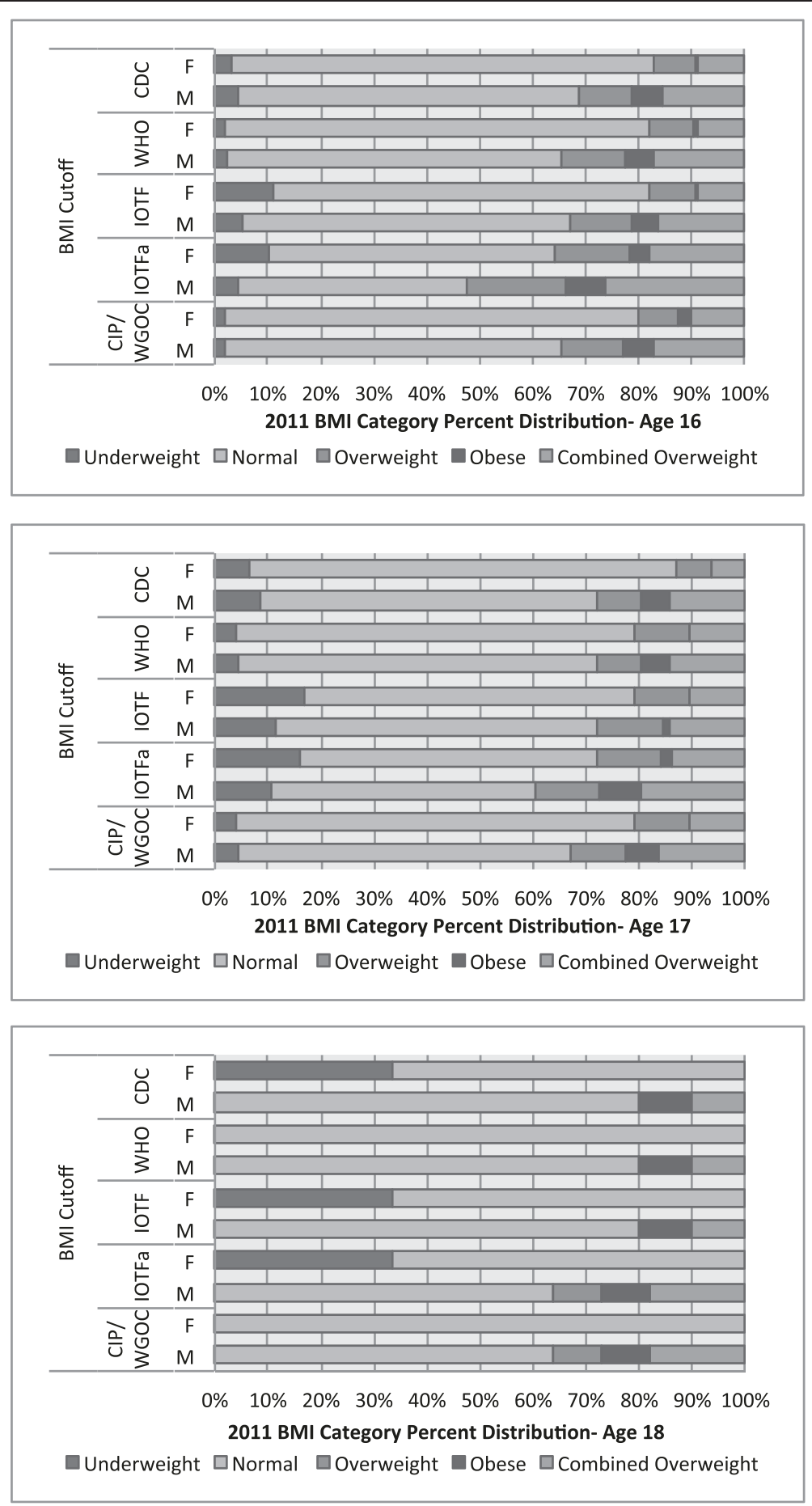

Figure 3 Percentage distributions of BMI categories among 5 different BMI cutoffs adjusting for gender and age for students aged 16 to 18 .

hours. The wet market stalls are independently rented and operated, and hence may only be open during early morning and late afternoons, or only on certain days. This may affect food accessibility for some populations, such as workers and students. Further, the era of the wet market may be coming to an end. During our field study in Kunming we visited a few internationally owned 'mega supermarkets.' In the summer of 2011, there were three Wal-Mart and six Carrefour mega stores in the city. These mega stores all allocated a large proportion of their 
Table 11 Numbers and percentage of cohort and their average BMIs in different regions of the city adjusting for gender and age

\begin{tabular}{|c|c|c|c|c|c|c|c|c|c|c|c|c|}
\hline \multirow[t]{4}{*}{ Age, yr } & \multicolumn{12}{|c|}{ Home location } \\
\hline & \multicolumn{4}{|c|}{ Within 1st ring } & \multicolumn{4}{|c|}{ Between the 1 st and 2 nd ring } & \multicolumn{4}{|c|}{ Outside the 2 nd ring } \\
\hline & \multicolumn{2}{|c|}{ Male } & \multicolumn{2}{|c|}{ Female } & \multicolumn{2}{|r|}{ Male } & \multicolumn{2}{|c|}{ Female } & \multicolumn{2}{|c|}{ Male } & \multicolumn{2}{|c|}{ Female } \\
\hline & N (\%) & $\overline{\text { Avg BMI (SD) }}$ & N (\%) & $\overline{A v g ~ B M I ~(S D) ~}$ & N (\%) & $\overline{\text { Avg BMI (SD) }}$ & N (\%) & $\overline{A v g ~ B M I ~(S D) ~}$ & N (\%) & $\overline{A v g ~ B M I ~(S D) ~}$ & N (\%) & $\overline{A v g}$ BMI (SD) \\
\hline 13 & 0 & 0 & 0 & 0 & 0 & 0 & 0 & 0 & 0 & 0 & $1(0.5)$ & $19.3(\mathrm{~N} / \mathrm{A})$ \\
\hline 14 & 0 & 0 & 0 & 0 & 0 & 0 & $2(2.6)$ & 24.7 (3.08) & 0 & 0 & $1(0.5)$ & $22.9(\mathrm{~N} / \mathrm{A})$ \\
\hline 15 & 0 & 0 & $3(8.3)$ & $20.1(1.51)$ & $1(1.5)$ & 19.7 (N/A) & $5(6.5)$ & $21.3(3.50)$ & $4(3.0)$ & $19.5(1.46)$ & $11(5.6)$ & $20.7(1.82)$ \\
\hline 16 & $28(71.8)$ & $21.7(3.58)$ & $30(83.3)$ & $21.6(3.11)$ & $45(68.2)$ & $21.4(3.97)$ & $58(75.3)$ & 20.5 (2.78) & $93(70.5)$ & $21.3(3.83)$ & $152(77.9)$ & $20.8(2.55)$ \\
\hline 17 & $11(28.2)$ & $21.9(2.46)$ & $3(8.3)$ & $19.4(1.24)$ & $18(27.3)$ & $21.7(4.45)$ & $11(14.3)$ & $21.5(2.71)$ & $28(21.2)$ & $21.3(3.33)$ & $28(14.4)$ & $20.7(2.70)$ \\
\hline 8 and above & 0 & 0 & 0 & 0 & $2(3.0)$ & $22.8(2.84)$ & $1(1.3)$ & $17.4(\mathrm{~N} / \mathrm{A})$ & $7(5.3)$ & $23.8(7.43)$ & $2(1.0)$ & $19.3(0.03)$ \\
\hline Total & $39(100)$ & $21.8(3.27)$ & $36(100)$ & $21.3(2.95)$ & $66(100)$ & $21.5(4.01)$ & 77 (100) & $20.8(2.86)$ & $132(100)$ & $21.4(3.95)$ & $195(100)$ & $20.8(2.51)$ \\
\hline
\end{tabular}

Percentage of students aged 16-17 and their average BMls in different regions of the city were BOLD as more than $85 \%$ of the students were between ages 16 and 17 . 
Table 12 Numbers and percentage of cohort that is overweight or obese in different regions of the city for various BMI cutoffs

\begin{tabular}{|c|c|c|c|c|c|c|c|c|c|c|c|c|}
\hline \multicolumn{13}{|c|}{ Age 14} \\
\hline \multirow{3}{*}{$\begin{array}{l}\text { Home } \\
\text { location }\end{array}$} & \multicolumn{4}{|c|}{$\begin{array}{l}\text { Within the 1st } \\
\text { ring }\end{array}$} & \multicolumn{4}{|c|}{$\begin{array}{l}\text { Between the 1st } \\
\text { and 2nd ring }\end{array}$} & \multicolumn{4}{|c|}{$\begin{array}{c}\text { Outside the 2nd } \\
\text { ring }\end{array}$} \\
\hline & \multicolumn{2}{|c|}{$N=0$} & \multicolumn{2}{|c|}{$N=0$} & \multicolumn{2}{|c|}{$N=0$} & \multicolumn{2}{|c|}{$\mathrm{N}=2$} & \multicolumn{2}{|c|}{$N=0$} & \multicolumn{2}{|c|}{$N=1$} \\
\hline & $M$ & $\%$ & $\mathrm{~F}$ & $\%$ & $M$ & $\%$ & $F$ & $\%$ & $M$ & $\%$ & $F$ & $\%$ \\
\hline $\begin{array}{l}\text { CIP/ } \\
\text { WGOC }\end{array}$ & 0 & 0 & 0 & 0 & 0 & 0 & 1 & 50.0 & 0 & 0 & 0 & 0.0 \\
\hline IOTFa & 0 & 0 & 0 & 0 & 0 & 0 & 2 & 100.0 & 0 & 0 & 1 & 100.0 \\
\hline IOTF & 0 & 0 & 0 & 0 & 0 & 0 & 1 & 50.0 & 0 & 0 & 0 & 0.0 \\
\hline WHO & 0 & 0 & 0 & 0 & 0 & 0 & 1 & 50.0 & 0 & 0 & 1 & 100.0 \\
\hline CDC & 0 & 0 & 0 & 0 & 0 & 0 & 1 & 50.0 & 0 & 0 & 0 & 0.0 \\
\hline
\end{tabular}

Age 15

\begin{tabular}{|c|c|c|c|c|c|c|c|c|c|c|c|c|}
\hline \multirow{3}{*}{$\begin{array}{l}\text { Home } \\
\text { location } \\
\text { BMI } \\
\text { cutoffs }\end{array}$} & \multicolumn{4}{|c|}{$\begin{array}{c}\text { Within the 1st } \\
\text { ring }\end{array}$} & \multicolumn{4}{|c|}{$\begin{array}{l}\text { Between the } 1 \text { st } \\
\text { and } 2 \text { nd ring }\end{array}$} & \multicolumn{4}{|c|}{$\begin{array}{c}\text { Outside the 2nd } \\
\text { ring }\end{array}$} \\
\hline & \multicolumn{2}{|c|}{$N=0$} & \multicolumn{2}{|c|}{$\mathrm{N}=3$} & \multicolumn{2}{|c|}{$N=1$} & \multicolumn{2}{|c|}{$N=5$} & \multicolumn{2}{|c|}{$N=3$} & \multicolumn{2}{|c|}{$\mathrm{N}=11$} \\
\hline & $M$ & $\%$ & $F$ & $\%$ & $M$ & $\%$ & $F$ & $\%$ & $M$ & $\%$ & $F$ & $\%$ \\
\hline $\begin{array}{l}\text { CIP/ } \\
\text { WGOC }\end{array}$ & 0 & 0 & 0 & 0 & 0 & 0 & 2 & 40.0 & 0 & 0 & 1 & 9.1 \\
\hline IOTFa & 0 & 0 & 0 & 0 & 0 & 0 & 2 & 40.0 & 0 & 0 & 3 & 27.3 \\
\hline IOTF & 0 & 0 & 0 & 0 & 0 & 0 & 1 & 20.0 & 0 & 0 & 1 & 9.1 \\
\hline WHO & 0 & 0 & 0 & 0 & 0 & 0 & 2 & 40.0 & 0 & 0 & 1 & 9.1 \\
\hline CDC & 0 & 0 & 0 & 0 & 0 & 0 & 1 & 20.0 & 0 & 0 & 1 & 9.1 \\
\hline
\end{tabular}

\begin{tabular}{|c|c|c|c|c|c|c|c|c|c|c|c|c|}
\hline \multirow{3}{*}{$\begin{array}{l}\text { Home } \\
\text { location }\end{array}$} & \multicolumn{4}{|c|}{$\begin{array}{l}\text { Within the 1st } \\
\text { ring }\end{array}$} & \multicolumn{4}{|c|}{$\begin{array}{l}\text { Between the 1st } \\
\text { and } 2 \text { nd ring }\end{array}$} & \multicolumn{4}{|c|}{$\begin{array}{c}\text { Outside the 2nd } \\
\text { ring }\end{array}$} \\
\hline & \multicolumn{2}{|c|}{$\mathrm{N}=\mathbf{2 8}$} & \multicolumn{2}{|c|}{$\mathrm{N}=30$} & \multicolumn{2}{|c|}{$\mathrm{N}=45$} & \multicolumn{2}{|c|}{$\mathrm{N}=58$} & \multicolumn{2}{|c|}{$\mathrm{N}=93$} & \multicolumn{2}{|c|}{$\mathrm{N}=152$} \\
\hline & $M$ & $\%$ & $F$ & $\%$ & $M$ & $\%$ & $\mathrm{~F}$ & $\%$ & $M$ & $\%$ & $F$ & $\%$ \\
\hline CIP/ & 6 & & 7 & & 7 & & 6 & & 22 & & 14 & \\
\hline IOTFa & 11 & & 9 & 30.0 & 15 & & 15 & & 31 & 33.3 & 28 & \\
\hline OTF & 5 & 17.9 & 7 & 23.3 & 6 & 13.3 & 5 & 8.6 & 22 & 23.7 & 12 & 7.9 \\
\hline / & 6 & 21.4 & 7 & 23.3 & 7 & 15.6 & 5 & 8.6 & 22 & 23.7 & 12 & 7.9 \\
\hline DC & 5 & 17.9 & 7 & 23.3 & 6 & 13.3 & 5 & 8.6 & 20 & 21.5 & 12 & 7.9 \\
\hline \multicolumn{13}{|c|}{ Age 17} \\
\hline & \multicolumn{4}{|c|}{$\begin{array}{c}\text { Within the 1st } \\
\text { ring }\end{array}$} & \multicolumn{4}{|c|}{$\begin{array}{l}\text { Between the 1st } \\
\text { and } 2 \text { nd ring }\end{array}$} & \multicolumn{4}{|c|}{$\begin{array}{c}\text { Outside the 2nd } \\
\text { ring }\end{array}$} \\
\hline & \multicolumn{2}{|c|}{$\mathrm{N}=11$} & \multicolumn{2}{|c|}{$N=3$} & \multicolumn{2}{|c|}{$\mathrm{N}=18$} & \multicolumn{2}{|c|}{$\mathrm{N}=11$} & \multicolumn{2}{|c|}{$\mathrm{N}=\mathbf{2 8}$} & \multicolumn{2}{|c|}{$\mathrm{N}=\mathbf{2 8}$} \\
\hline $\mathrm{Ml}$ & M & $\%$ & $F$ & $\%$ & $M$ & $\%$ & $F$ & $\%$ & $M$ & $\%$ & $\mathrm{~F}$ & $\%$ \\
\hline IP/ & 2 & & 0 & 0 & 5 & & 2 & & 4 & 14.3 & 3 & \\
\hline IOTFa & 3 & 27.3 & 0 & 0 & 6 & 33.3 & 3 & 27.3 & 6 & 21.4 & 4 & 14.3 \\
\hline OTF & 2 & 18.2 & 0 & 0 & 5 & 27.8 & 2 & 18.2 & 3 & 10.7 & 3 & 10.7 \\
\hline $\mathrm{VHO}$ & 2 & 18.2 & 0 & 0 & 5 & 27.8 & 2 & 18.2 & 3 & 10.7 & 3 & 10.7 \\
\hline DC & 2 & 18.2 & 0 & 0 & 5 & 27.8 & 2 & 18.2 & 3 & 10.7 & 1 & 3.6 \\
\hline
\end{tabular}

Table 12 Numbers and percentage of cohort that is overweight or obese in different regions of the city for various BMI cutoffs (Continued)

\begin{tabular}{|c|c|c|c|c|c|c|c|c|c|c|c|c|}
\hline \multicolumn{13}{|c|}{ Age 18 and above } \\
\hline \multirow[t]{2}{*}{$\begin{array}{l}\text { Home } \\
\text { location }\end{array}$} & \multicolumn{4}{|c|}{$\begin{array}{c}\text { Within the 1st } \\
\text { ring }\end{array}$} & \multicolumn{4}{|c|}{$\begin{array}{l}\text { Between the 1st } \\
\text { and 2nd ring }\end{array}$} & \multicolumn{4}{|c|}{$\begin{array}{c}\text { Outside the } 2 \mathrm{nc} \\
\text { ring }\end{array}$} \\
\hline & \multicolumn{2}{|c|}{$\mathrm{N}=0$} & \multicolumn{2}{|c|}{$\mathrm{N}=0$} & \multicolumn{2}{|c|}{$\mathrm{N}=2$} & \multicolumn{2}{|c|}{$N=1$} & \multicolumn{2}{|c|}{$N=7$} & \multicolumn{2}{|c|}{$\mathrm{N}=\mathbf{2}$} \\
\hline $\begin{array}{l}\text { BMI } \\
\text { cutoffs }\end{array}$ & M & $\%$ & $\mathrm{~F}$ & $\%$ & M & $\%$ & $\mathrm{~F}$ & $\%$ & M & $\%$ & $\mathrm{~F}$ & $\%$ \\
\hline $\begin{array}{l}\text { CIP/ } \\
\text { WGOC }\end{array}$ & 0 & 0 & 0 & 0 & 1 & 50.0 & 0 & 0 & 1 & 14.3 & 0 & 0 \\
\hline IOTFa & 0 & 0 & 0 & 0 & 1 & 50.0 & 0 & 0 & 1 & 14.3 & 0 & 0 \\
\hline IOTF & 0 & 0 & 0 & 0 & 0 & 0 & 0 & 0 & 1 & 14.3 & 0 & 0 \\
\hline WHO & 0 & 0 & 0 & 0 & 0 & 0 & 0 & 0 & 1 & 14.3 & 0 & 0 \\
\hline $\mathrm{CDC}$ & 0 & 0 & 0 & 0 & 0 & 0 & 0 & 0 & 1 & 14.3 & 0 & 0 \\
\hline
\end{tabular}

Percentage of students aged 16-17 and their average BMls in different regions of the city were BOLD as more than $85 \%$ of the students were between ages 16 and 17 .

shelves to food products. Although we were not allowed by management to conduct our survey in their stores, we observed food delis that served many different types of cooked foods. Additionally, we observed aisle after aisle of packaged and fresh foods. Fresh fruits and vegetables were sold individually as well as in convenience packages - prewashed (Figure 4) and bundled for quick meal preparation. The prices were comparable to the wet markets, and the stores were packed with customers when we visited.

Our study is one of the few that present data on adolescent BMIs for middle-sized cities in western China. Adolescents who lived in the inner neighborhoods of Kunming tended to have higher percentage of overweight indicating the surveys were valid in assessing food environment - obesity relationships. Specifically, adolescents who live within the $1^{\text {st }}$ ring tended to have higher western-style fast food and packaged food exposures or unhealthy food environment exposures than those who live between the $1^{\text {st }}$ and $2^{\text {nd }}$ ring and those who live outside the $2^{\text {nd }}$ ring. While obesity is complex and affected by many factors such as built environment characteristics and socio-demographic status, even when unadjusted for confounding factors, differences in the food environment tended to be associated with observed differences in the rates of adolescent overweight and obese between neighborhoods. Additional research is needed to determine whether this association may be due to potential confounding factors (e.g., access to physical activity environments, environmental stress, etc.), rather than the food environment. As we consider future multivariate analyses of the associations between neighborhood-level differences and BMI, there may be value in considering BMI as a continuous variable in regression analyses to avoid loss of information through 

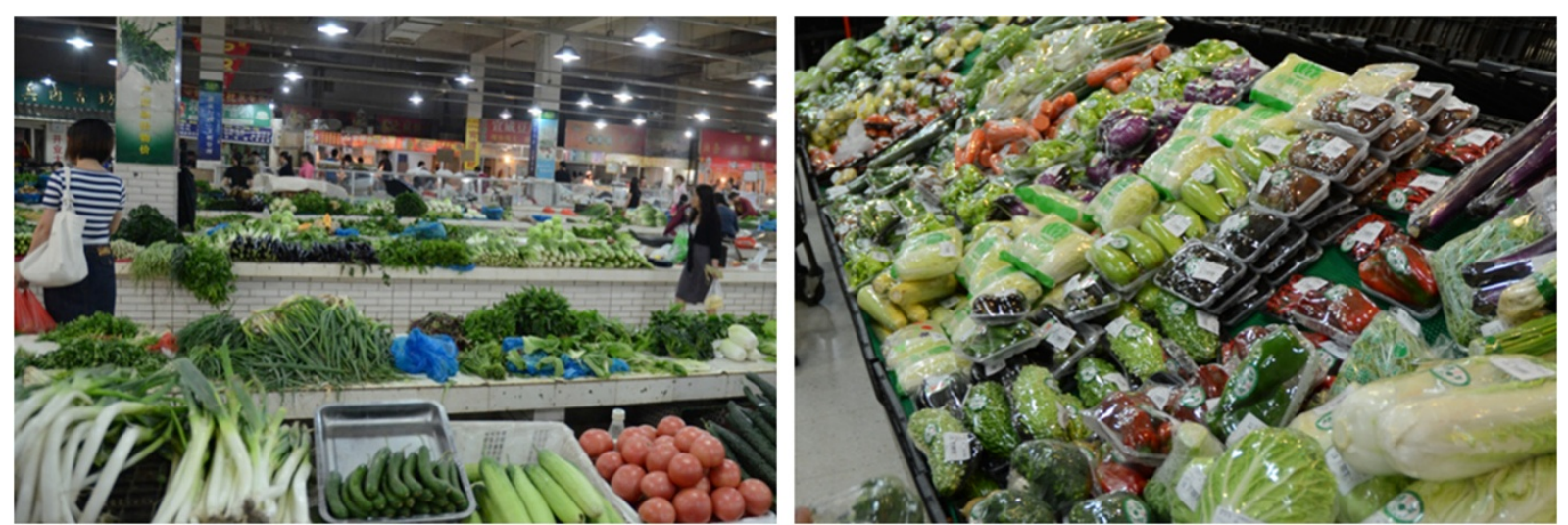

Figure 4 Vegetables sold in the wet market (left) compared to those sold in the mega-supermarket (right).

the tricotomization of BMI into underweight, normal, and overweight categories. Moreover, there would be considerable value in collecting actual data on dietary patterns as a mediator between the food environment and obesity. Ongoing research by our group aims to further explore the linkages between the food environment, dietary behavior, and weight status for adolescents. Nevertheless, our current findings are consistent with several studies that demonstrated that proximity to fast foods is positively associated with diet and higher BMI in Western contexts [23,42-50].

Different BMI cutoffs generated slight to moderate differences in the distributions of overweight and obese categories. IOTF Asian cutoff generated the highest percentages of overweight adolescents (35.6\% for males and $21.8 \%$ for females) whereas CDC cutoffs only generated $18.6 \%$ for males and $9.5 \%$ for females, less than half of the IOTF Asian cutoff. In terms of underweight adolescents, CIP and WHO cutoffs generated around 2.0\% of underweight males and females, whereas IOTF cutoff generated $6.2 \%$ for males and $12.3 \%$ for females, about three times and six times higher than the WHO percentage, respectively. Therefore, it is important for researchers to consider different cutoffs, and their use on particular populations. Choosing appropriate cutoffs will be extremely important in developing intervention strategies and making policy recommendations. Regardless of the BMI cutoffs used, however, we found the prevalence of overweight adolescents worrying, especially for male adolescents. Should these findings be reinforced by other larger studies in Chinese cities, action in the form of new obesity prevention strategies may be warranted to combat this problem.

\section{Conclusions}

The rates of overweight and obesity among Chinese adolescents deserves immediate attention, and requires the development of reliable, valid, and culturally-appropriate instruments to track risk factors for obesity. To our knowledge, this is the first food environment survey instrument developed to specifically assess changing food availability, accessibility and pricing in China. Moreover, this is one of the few studies that provide insights into rates of adolescent overweight/obesity in a middle-sized city in western China. This instrument can be used for conducting systematic longitudinal assessments of the changing food environment in rapidly developing Chinese cities where there is an urgent need to monitor changing disease risk.

\section{Additional file}

Additional file 1: Percentage distribution of BMI categories among
$\mathbf{5}$ different BMI cutoffs adjusting for gender and age. Word
document: this table was too large to be included in the main text.

\section{Abbreviations}

CIP: Capital Institute of Pediatrics; WGOC: Working Group on Obesity in China; IOTFa: International obesity task force Asian cutoff; IOTF: International Obesity Task Force; WHO: World Health Organization; CDC: Center for disease control.

\section{Competing interests}

The authors declare that they have no competing interests.

\section{Authors' contributions}

All authors were involved in various stages of study design, survey development and validation. JH carried out the fieldwork and wrote the paper. $\mathrm{JH}$ and ES conducted the statistical analysis. ES, YL and MW oversaw the study progress and ensured the successful survey field deployment. All authors commented on drafts and approved the final text.

\section{Acknowledgements}

This project was supported by the California Center for Population Research (CCPR) at the University of California Los Angeles, the Center for

Occupational and Environmental Health (COEH), the Center for Global Public Health (CGPH) at University of California Berkeley, and the Fulbright Program. The authors would like to thank Anna Dong, Mao Yin, Zhenzhen Ruan, Wei Xie, Fangqing Wei, Rufei Duan, and Xiaojie Gong, graduate students at Kunming Medical College whose hard work made this project possible. The authors would also like to thank Patricia Crawford for reading and editing the draft of this manuscript and her constructive remarks. 


\section{Author details}

${ }^{1}$ School of Public Health, University of California, Berkeley, CA, USA. ${ }^{2}$ School of Public Health, University of Washington, Seattle, WA, USA. ${ }^{3}$ Kunming Medical University, Kunming, China. ${ }^{4}$ Fielding School of Public Health University of California, Los Angeles, CA, USA

Received: 17 June 2013 Accepted: 24 February 2014

Published: 6 March 2014

\section{References}

1. Ogden $\mathrm{CL}$, Carroll MD, Kit BK, Flegal KM: Prevalence of obesity and trends in body mass index among US children and adolescents, 1999-2010. JAMA 2012, 307(5):483-490.

2. Flegal KM, Carroll MD, Kit BK, Ogden CL: Prevalence of obesity and trends in the distribution of body mass index among US adults, 1999-2010. JAMA 2012, 307(5):491-497.

3. Finkelstein EA, Trogdon JG, Cohen JW, Dietz W: Annual medical spending attributable to obesity: payer-and service-specific estimates. Health Aff 2009, 28(5):w822-831.

4. World Health Organization (WHO): Controlling the global obesity epidemicThe challenge; 2012.

5. Durand CP, Andalib M, Dunton GF, Wolch J, Pentz MA: A systematic review of built environment factors related to physical activity and obesity risk: implications for smart growth urban planning. Obes Rev 2011, 12(5):e173-182.

6. Frank LD, Saelens BE, Powell KE, Chapman JE: Stepping towards causation: do built environments or neighborhood and travel preferences explain physical activity, driving, and obesity? Soc Sci Med 2007, 65(9):1898-1914.

7. Larson N, Story M: A review of environmental influences on food choices. Ann Behav Med 2009, 38(Suppl 1):S56-73.

8. Ji CY, Cheng TO: Epidemic increase in overweight and obesity in Chinese children from 1985 to 2005. Int J Cardiol 2009, 132(1):1-10.

9. Chen S, Binns CW, Zhang Y: The importance of definition in diagnosing obesity: a review of studies of children in china. Asia Pac J Public Health 2012, 24(2):248-262

10. Cai L, Shu ZK, Lu YC, Tao J, Yan F, Ye YH, Zhang P: Prevalence of overweight and central obesity and the relationship with cardiovascular diseases among rural residents in Kunming. Mod Preventative Med 2010, 37(19):3601-3609.

11. Zhu K, Pu B, Xu X: Epidemiological survey on simple obesity in $0 \sim 7$ years old children in Kunming city. Chin J Public Health 2008, 16:280-284.

12. Chen CM: Overview of obesity in Mainland China. Obes Rev 2008, 9(Suppl 1):14-21.

13. Fletcher A, Bonell C, Sorhaindo A: You are what your friends eat: systematic review of social network analyses of young people's eating behaviors and bodyweight. J Epidemiol Community Health 2011, 65(6):548-555.

14. Li Y, Schouten EG, Hu X, Cui Z, Luan D, Ma G: Obesity prevalence and time trend among youngsters in China, 1982-2002. Asia Pac J Clin Nutr 2008, 17(1):131-137.

15. Zhang M, Li Z, Qiu H, Zhang MR, Li ZK, Ma Y, Yang Z, Shen L, Liu Y, Tian R: Study on the epidemiological characteristics of overweight and obesity in Kunming. Chin Prim Health Care 2009, 23(4):68-70.

16. Block JP, Christakis NA, O'Malley AJ, Subramanian SV: Proximity to food establishments and body mass index in the Framingham Heart Study offspring cohort over 30 years. Am J Epidemiol 2011, 174(10):1108-1114.

17. Fleischhacker SE, Evenson KR, Rodriquez DA, Ammerman AS: A systematic review of fast food access studies. Obes Rev 2011, 12(5):e460-471.

18. Holsten JE: Obesity and the community food environment: a systematic review. Public Health Nutr 2009, 12(3):397-405.

19. Wang M, Kim S, Gonzalez A, MacLeod K, Winkleby M: Socioeconomic and food-related physical characteristics of the neighbourhood environment are associated with body mass index. J Epidemiol Commun Health 2007 61(6):491-498

20. Morland K, Diez Roux AV, Wing S: Supermarkets, other food stores, and obesity: the atherosclerosis risk in communities study. Am J Preventive Med 2006, 30(4):333-339

21. Bader MD, Ailshire JA, Morenoff JD, House JS: Measurement of the local food environment: a comparison of existing data sources. Am J Epidemiol 2010, 171(5):609-617.

22. Gustafson A, Hankins S, Jilcott S: Measures of the consumer food store environment: a systematic review of the evidence 2000-2011. J Commun Health 2012, 37(4):897-911.
23. Kelly B, Flood VM, Yeatman H: Measuring local food environments: an overview of available methods and measures. Health Place 2011, 17(6):1284-1293

24. Lytle LA: Measuring the food environment: state of the science. Am J Preventive Med 2009, 36(4 Suppl):S134-144

25. Glanz K, Sallis JF, Saelens BE, Frank LD: Nutrition Environment Measures Survey in stores (NEMS-S): development and evaluation. Am J Preventive Med 2007, 32(4):282-289.

26. Hosler AS, Dharssi A: Reliability of a survey tool for measuring consumer nutrition environment in urban food stores. J Public Health Manag Pract 2011, 17(5):E1-8.

27. Ohri-Vachaspati $P$, Leviton LC: Measuring food environments: a guide to available instruments. J Public Health Manag Pract 2010, 24(6):410-426.

28. Saelens BE, Glanz K, Sallis JF, Frank LD: Nutrition Environment Measures Study in restaurants (NEMS-R): development and evaluation. Am J Preventive Med 2007, 32(4):273-281.

29. Office of Management and Budget (OMB): North American Industry Classification System; 2007 [http://www.census.gov/cgi-bin/sssd/naics/ naicsrch?chart=2007]

30. Zhu K, Pu B, Xu X: Epidemiological survey on simple obesity in $0 \sim 7$ years old children in Kunming city. Chin J Child Health Care 2008 16(6):696-698

31. Liu WMLJ, Guo BZ: The changing trend of detection rate of collective obesity in children under 7 in Kunming from 2002 to 2007. J Kunming Med University 2011, 3:73-75

32. Zhang H: Four Neighborhood Comparison Survey. In. Kunming, Yunnan, China: Yunnan University of Finance and Economics; 2011.

33. Ji CY: Report on childhood obesity in China (1)-body mass index reference for screening overweight and obesity in Chinese school-age children. Biomedical Environ Sci 2005, 18(6):390-400.

34. International Association for the Study of Obesity: Extended international (IOTF) body mass index cut-offs for thinness, overweight and obesity in children. [http://www.iaso.org/resources/aboutobesity/child-obesity/ newchildcutoffs/]

35. Cole TJ, Lobstein T: Extended international (IOTF) body mass index cutoffs for thinness, overweight and obesity. Pediatric Obesity 2012, 7(4):284-294.

36. World Health Organization (WHO): Growth reference 5-19 Years, BMl-forage (5-19 years). 2007 [http://www.who.int/growthref/ who2007_bmi_for_age/en/index.html]

37. Butte NF, Garza C, de Onis M: Evaluation of the feasibility of international growth standards for school-aged children and adolescents. J Nutr 2007 137(1):153-157.

38. Center for Disease Control and Prevention and National Center for Health Statistics: Clinical Growth Charts; 2009 [http://www.cdc.gov/growthcharts/ clinical_charts.htm]

39. Kuczmarski RJ, Ogden CL, Guo SS, Grummer-Strawn LM, Flegal KM, Mei Z, Wei R, Curtin LR, Roche AF, Johnson CL: CDC Growth Charts for the United States: methods and development. Vital Health Stat Series 11, Data National Health Surv 2000, 2002(246):1-190.

40. Li H, Ji CY, Zong XN, Zhang YQ: [Body mass index growth curves for Chinese children and adolescents aged 0 to 18 years]. Zhonghua Er Ke Za Zhi Chin J Pediatr 2009, 47(7):493-498.

41. Li H, Ji CY, Zong XN, Zhang YQ: Height and weight standardized growth charts for Chinese children and adolescents aged 0 to 18 years. Zhonghua Er Ke Za Zhi Chin J Pediatr 2009, 47(7):487-492.

42. Caspi CE, Sorensen G, Subramanian SV, Kawachi I: The local food environment and diet: a systematic review. Health Place 2012, 18(5):1172-1187

43. Charreire H, Casey R, Salze P, Simon C, Chaix B, Banos A, Badariotti D, Weber C, Oppert JM: Measuring the food environment using geographical information systems: a methodological review. Public Health Nutr 2010 13(11):1773-1785.

44. McKinnon RA, Reedy J, Morrissette MA, Lytle LA, Yaroch AL: Measures of the food environment: a compilation of the literature, 1990-2007. Am J Prev Med 2009, 36(4 Suppl):S124-133.

45. Morland K, Wing S, Diez Roux A: The contextual effect of the local food environment on residents' diets: the atherosclerosis risk in communities study. Am J Public Health 2002, 92(11):1761-1767.

46. Boone-Heinonen J, Gordon-Larsen P, Kiefe Cl, Shikany JM, Lewis CE, Popkin BM: Fast food restaurants and food stores: longitudinal associations with 
diet in young to middle-aged adults: the CARDIA study. Arch Intern Med 2011, 171(13):1162-1170.

47. Moore LV, Diez Roux AV, Nettleton JA, Jacobs DR, Franco M: Fast-food consumption, diet quality, and neighborhood exposure to fast food: the multi-ethnic study of atherosclerosis. Am J Epidemiol 2009, 170(1):29-36.

48. Hickson DA, Diez Roux AV, Smith AE, Tucker KL, Gore LD, Zhang L, Wyatt SB; Associations of fast food restaurant availability with dietary intake and weight among African Americans in the Jackson Heart Study, 2000-2004. Am J Public Health 2011, 101 (Suppl 1):S301-309.

49. Jennings $A$, Welch A, Jones AP, Harrison F, Bentham $G$, van Sluijs EM, Griffin SJ, Cassidy A: Local food outlets, weight status, and dietary intake: associations in children aged 9-10 years. Am J Prev Med 2011, 40(4):405-410.

50. Timperio A, Ball K, Roberts R, Campbell K, Andrianopoulos N, Crawford D: Children's fruit and vegetable intake: associations with the neighbourhood food environment. Preventive Med 2008, 46(4):331-335.

doi:10.1186/1471-2458-14-235

Cite this article as: Hua et al:: Development and evaluation of a food environment survey in three urban environments of Kunming, China. BMC Public Health 2014 14:235.

\section{Submit your next manuscript to BioMed Central} and take full advantage of:

- Convenient online submission

- Thorough peer review

- No space constraints or color figure charges

- Immediate publication on acceptance

- Inclusion in PubMed, CAS, Scopus and Google Scholar

- Research which is freely available for redistribution

Submit your manuscript at www.biomedcentral.com/submit

C Biomed Central 